\title{
Enzymatic Antioxidants: Next Phase of Pharmacological Effort to Fight Oxidative Stress?
}

\author{
Alexander V. Maksimenko*, Alexander V. Vavaev and Elena G. Tischenko \\ Institute of Experimental Cardiology, Russian Cardiology Research-and-Production Complex, 15A, 3rd Cherepkovskaja \\ Str., 121552 Moscow, Russia
}

\begin{abstract}
The focus in the research of antioxidants is notably displaced in favour of research of enzyme derivatives. Extracellular superoxide dismutase (EC-SOD) is of the particular interest, as it demonstrates in vivo the protective action against development of atherosclerosis, hypertension, heart failure, diabetes mellitus. The reliable association of coronary artery disease with the decreased level of heparin-released EC-SOD was established in clinical researches. To base and develop antioxidant therapy, various SOD isozymes, catalase (CAT), the methods of experimental gene therapy, combined application of SOD- and CAT-activities are used. Covalent bienzyme SOD - CHS - CAT conjugate (where CHS - chondroitin sulphate) showed in the experimental trials its high efficacy as the antithrombotic agent. Pre-clinical research data approve the reliable option to gain for it the status of drug candidate. The trend to use the components of glycocalyx and extracellular matrix for target delivery of medical substances is evident. Development of new enzyme antioxidants for therapeutical destination is closely connected with becoming and progress of medical biotechnology, pharmaceutical industry, bioeconomy.
\end{abstract}

Keywords: Enzyme antioxidants, oxidative stress, cardiovascular diseases, extracellular superoxide dismutase, catalase.

\section{INTRODUCTION}

The unabated actuality of medical withstanding to the cardiovascular diseases is determined with their wide spreading. Reperfusion therapy has become the efficient means of response for acute and threatening manifestations of the cardiovascular disorders. It is based on application of thrombolytic effect and stent and/or balloon therapy at the damaged part of the vascular bed. Such interventions proved to be very efficient for restriction of size of acute myocardial infarction (AMI), one of the most serious lesions of the cardiovascular system. The size of myocardial infarction is the principal factor of prognosis for the patients with AMI. Reperfusion therapy itself allows restricting the size of AMI up to $50 \%$ of ischemic region [1]. One of four patients with AMI has the size of lesion exceeding $75 \%$ of the risk zone. There is the opinion that the lesion of the left ventricle exceeding 20\% results in stable and reliable prognosis of vulnerability to morbidity and mortality. Such situation resulted in need to find the medical resources to decrease the size of AMI from fatal $75 \%$ of ischemic region to $40 \%$ and less [1]; that is especially important for the most serious cases. The certain limitation of reserves of reperfusion therapy determines the justified task to develop the methods and means of adjacent treatment [2] contributing to restriction of size of AMI and increase of survival index from the estimated rate of 0.25 (typical for use of reperfusion therapy only) to the value of 0.60 and more [1].

*Address correspondence to this author at the Institute of Experimental Cardiology, Russian Cardiology Research-and-Production Complex, 15A, 3rd Cherepkovskaja Str., 121552 Moscow, Russia; Tel: 7-495-414-60-25; Fax: 7-499-726-31-16; E-mail: alexmak@cardio.ru
The role of the oxidative stress in development of cardiovascular injuries was reliably established $[3,4]$. One of the objectives of adjacent (additional) therapy is to block it. The oxidative stress contributes to the aggravation of disorders during thrombolysis for potency of infarct-related artery ("reperfusion injury") [5, 6], during vascular angioplasty procedures (development of restenosis) [7, 8]. That's why the importance of search of highly efficient resources to ensure antioxidant protection of the cardiovascular system is well known and justified.

\section{EXPERIMENTAL AND CLINICAL ANTIOXIDANT RESEARCH}

Efficiency of use of antioxidant derivatives in response to the destructive action of oxidative stress was shown in numerous experimental researches on animals and cells [9]. Nevertheless, the clinical trial data had not confirmed their universal efficiency established in experimental researches $[10,11]$. Inconsistency of the clinical results of testing antioxidants was explained by difference of the used models of lesions on animals and cell from the human body environment [1, 5], by incorrect choice of the tested antioxidant, parameters of monitoring its activity, amounts of the injected derivative doses, duration of trials, patient selection criteria $[9,11]$. Such situation determines the necessity to perform new clinical trials according to the strict protocol with more wide use of new antioxidant derivatives. Recalling the certain exhaustion of financial, organizational, scientific, medical resources, the future development of antioxidant therapy is possible in two directions. The first direction is connected with the accurate, step-by-step experimental and clinical trials of various antioxidants to collect gradually the critical mass of data on efficacy of antioxidant therapy in response to the accumulated 
scepticism of clinicians. The second direction is based on obtaining the bright and evident data of medical efficiency of antioxidants enabling to accelerate breakthrough in practice of methods and means of antioxidant therapy.

\section{WIDE SCOPE OF ANTIOXIDANT RESEARCH}

The study which continued in clinical trial seems to be the most attractive of all mass of enduring antioxidant researches. So, edaravone (3-methyl-1-phenyl-2-pyrazoline5 -one) was used (intravenous infusion $30 \mathrm{mg}$ during 10 minutes within six hours after manifestation of lesion symptoms) in process of stenting the arteries of patients with AMI confirmed by angiography [12]. It appeared that edaravone (to compare with the control group/physiological solution) inhibited almost all manifestations of reperfusion lesion, such as reperfusion arrhythmia, myocardium stunning, fatal reperfusion injury. Edaravone administration before reperfusion ensured smaller area of AMI by enzyme index (area under the curve of level of isozymes of creatine kinase e.g. CK-MB isoenzyme of the heart in serum) and better clinical data [12]. It should be mentioned that just due to inhibition of reactive oxygen forms which deplete the level of nitric oxide (NO) edaravone increased the bloodstream in the forearm of the smokers, acting on endothelium-related vascular dilatation [13]. The same was the target of co-enzyme $\mathrm{Q}_{10}$ action. It ameliorated bioenergetics parameters, increased the activity of extracellular superoxide dismutase (EC-SOD) and endothelium-related dilatation after one month of oral dose (300 $\mathrm{mg}$ per day) by the patients with coronary artery disease [14]. Clinical trials of food (diet) antioxidants (vitamins E, C, polyphenols, carotenoids/lycopine, beta-carotene/, co-enzyme $\mathrm{Q}_{10}$ ) are actively held now, aiming at prevention of atherogenic oxidation of low-density lipoproteins and oxidative damage of endothelium. These researches are focused on reveal of influence on activity of transcription factors (with definition of polymorphisms of the organism) and development of individual diets based on dietary antioxidants [15]. The mass of publications on the researches of low-molecular antioxidants remains tremendous still, but with the trend to decrease. On such background it is difficult not to note the splash of interesting publications dedicated to the curative effects of enzyme antioxidants.

\section{EXTRACELLULAR SUPEROXIDE DISMUTASE}

Increased content of superoxide radical $\left(\mathrm{O}_{\overline{2}}^{\overline{2}}\right)$ was noted in the arteries of spontaneously hypertensive rats; in this case genetic transfer of EC-SOD ameliorated endothelium function and decreased the arterial pressure [16]. Thus, interaction of $\mathrm{O}_{\overline{2}}$ with $\mathrm{NO}$ should primary have place in extracellular space [17]. Among all antioxidant enzymes only EC-SOD is localized on the surface of the vascular lumen, interacting with heparan sulphate proteoglycan (and also with collagen [18] and fibulin-5 [19]) by its heparanbinding domain $[10,17]$. EC-SOD may probably be located along the depth of the whole vascular wall, including the area between endothelium and vessel muscle [20]. Heparin injection (in concentrations used for the patients) leads to release to the bloodstream the EC-SOD bounded earlier by the endothelium cells and other tissues [17,21]. Antioxidant effect of EC-SOD appears mainly on the vascular wall, not inside the volume of the bloodstream [10, 17]. It was established that human coronary artery diseases are reliably connected with the decreased level of heparin-released ECSOD [22, 23]. Its positive correlation with the level of highdensity lipoprotein cholesterol and the age was noted [23]. Protective effect of EC-SOD is explained by protection of vessel dilatator NO which is diffusing from the endothelium cells to guanylatcyclase of the smooth muscle cells $[10,17$, 24]. This was approved by the data received from the model of high-volume hypertension in mice (1-kidney-1-clamp) [25]. Decline of dilatation connected with endothelium, increased arterial pressure and oxidative stress of the vessels are noted among wild mice and mice knocked-out with ECSOD. Recombinant EC-SOD decreased the arterial pressure and ameliorated bioavailability of NO in aorta of wild mice and of the mice knocked-out with EC-SOD. This enzyme antioxidant did not decrease the arterial pressure of the mice knocked-out with endothelium NO-synthase, and of the wild mice receiving NO-synthase inhibitor. These results evidently linked the vascular effect of recombinant EC-SOD on the NO-protection [25]. In line with the other data [26-28] they proved the important role of this biocatalyst in case of hypertension. Similarly to the cases of atherosclerosis [10, 17] and hypertension, the oxidative stress and enzyme antioxidants play an important role in development of diabetes mellitus and heart failure [17].

\section{EXPERIMENTAL STUDY OF ANTIOXIDANT GENE THERAPY}

The notable interest of researches to EC-SOD [16, 17, 20-28] that is the (SOD-3) tetramer of Cu,Zn-SOD with high affinity to heparan sulphate [29-31] in the mammals, or its dimer form of $\mathrm{Cu}, \mathrm{Zn}$-SOD with low affinity to heparan sulphate $[16,29,31]$ in the rats (as a result, the rats represent actually almost physiological knocked-out model for this enzyme) caused the development of gene therapy approaches aimed at ensuring antioxidant activity of the organism due to transfer of the appropriate genes [10,32]. Antioxidant gene therapy proved to be successful in experimental models of restenosis (rabbits, rats, pigs, etc.) with increase of expression of EC-SOD, cytosolic dimeric $\mathrm{Cu}, \mathrm{Zn}-\mathrm{SOD}$ (SOD-1), catalase (CAT), hemoxygenase-1. The later is the enzyme induced by the stress; it transforms hem in biliverdin (for its further metabolic transformation in bilirubin), $\mathrm{CO}$ and ions of iron $[32,33]$. The difficulties of clinical use of gene therapy are caused by limited duration of transgenic expression, but cardiovascular disorders (for example, atherosclerosis) develop during the decades, or, visa versa, occur spontaneously (plaque disruption, thrombosis). These factors make the criteria for patient selection, and the moment of treatment beginning unclear. Development of efficient methods of delivery of the gene material (limited transduction of cardiovascular cells), immunogenicity of the used delivery systems, distortion of redox status of cells required for the normal signalling [32] are also the important problems. On the background of these limitations local delivery of gene constructions looks to be the most efficient. Endothelium denudation of rabbits with placement of stent in damaged area, with simultaneous catheter injection of adenovirus with EC-SOD code (treatment group) or of betagalactosidase (control group) made it possible to establish (monitoring vascular histology, the level of active oxygen forms and expression) that EC-SOD significantly accelerated 
endothelium restoration and decreased the size of neointimal thickening [34]. Such information really represents local gene therapy as the promising strategy of response to the vessel lesions caused by artery stenting. Moreover, EC-SOD protein concentration in the hypertensive and normotensive subjects are indistinguishable, whereas hypertensive patients have significantly reduced plasma EC-SOD activity [35]. These data suggest that this reduction in EC-SOD activity is not due to a down-regulation of the SOD-3 gene. It should be noted also role of polymorphism of EC-SOD gene (on hypertension development in human) may be important for possible gene therapy in future.

\section{CONNECTION OF SUPEROXIDE DISMUTASE AND CATALASE ACTIVITY}

The wide scope of research of antioxidant protection with superoxide dismutases [17,21,29] naturally revealed in this case inactivation of endogenous enzyme by hydrogen peroxide [25]. Prolonged CAT treatment in vivo (intravenous bolus injection of derivative of catalase-polyethylene glycol during three days) decreased the blood pressure of spontaneously hypertensive wild mice (but not of the mice knocked-out without EC-SOD) and ameliorated ex vivo the function of aorta endothelium. These data evidently demonstrated the central role of hydrogen peroxide in inactivation of endogenous EC-SOD $[25,36]$. The efficiency of decrease of hydrogen peroxide level in case of the oxidative stress was shown on the cell cultures. Super expression of CAT protected endothelium of human aorta against apoptosis caused by the oxidized forms of lowdensity lipoproteins (oxLDL) [37]. Transfer (in the smooth muscle cells of human aorta) of SOD-1 and/or CAT genes inhibited their proliferation induced by oxLDL [38]. Super expression in mice of CAT or CAT together with SOD-1 inhibited development of atherosclerosis in mice [39], underlining the important role of hydrogen peroxide in atherogenesis and advisability of protection against oxidative stress of the vessels by simultaneous SOD- and CAT activity. Such properties were combined in EUK-8, the synthetic mimetic of SOD- and CAT-activity, containing Se and $\mathrm{Mn}$. This derivative has shown the protective effect (intra-abdominal injections $25 \mathrm{mg} / \mathrm{kg} / \mathrm{day}$, three times a day during four weeks) against remodelling of the left ventricle and cardiac decompensation in mice with model of development of heart failure [40]. These results may provide in future the chronic instrument of treatment of human heart failure; they confirm the efficiency of the combined effect of SOD- and CAT-activity in blocking the oxidative stress.

\section{COMBINATION OF SUPEROXIDE DISMUTASE WITH CATALASE}

Combined use of native forms of SOD and CAT provided the controversial data on antioxidant protection of the organism [10]. The simultaneous action of SOD and CAT in area of lesion development was required to demonstrate the reliable effect of treatment. It became possible due to the obtaining the bienzyme conjugate, where SOD-1 was covalently bounded through glycosaminoglycan of the vascular wall, chondroitin sulphate (CHS), with CAT (the received adduct SOD-CHS-CAT) [41]. Such conjugation contributed to likening of SOD-1 to SOD-3 (really, ECSOD is a glycoprotein [29-31]), and rendered to the received derivative biochemically coupled SOD- and CAT-activity (when the product of SOD reaction, hydrogen peroxide, is the substrate for the following CAT transformation in water and molecular oxygen being safe in such conditions; chemical reactions are given below).

$2\left[\mathrm{O}_{\dot{2}}^{-}+\mathrm{O}_{\dot{2}}^{-}+3 \mathrm{H}^{+}\right] \stackrel{\text { SOD }}{\longrightarrow} 3 \mathrm{H}_{2} \mathrm{O}_{2}+\mathrm{O}_{2}$
$\frac{\mathrm{H}_{2} \mathrm{O}_{2}+\mathrm{H}_{2} \mathrm{O}_{2} \stackrel{\mathrm{CAT}}{\longrightarrow} 2 \mathrm{H}_{2} \mathrm{O}+\mathrm{O}_{2}}{4 \mathrm{O}_{\overline{2}}^{-}+4 \mathrm{H}^{+} \stackrel{\text { SOD/CAT }}{\longrightarrow} 2 \mathrm{H}_{2} \mathrm{O}+3 \mathrm{O}_{2}}$

Schemes of reactions of catalyzed SOD and CAT.

On the model of arterial thrombosis in rats induced by treatment of vessel with saturated solution of ferrous chloride, the bienzyme SOD -CHS-CAT conjugate has shown antithrombotic effect in doses for two orders less than for the mix of native SOD and CAT, and for order less than for the mix of SOD and CAT modified by CHS. Crosslinking the proteins with $\mathrm{CHS}$ is to direct bienzyme conjugate to the areas of vessel lesions. It is well-known that the areas of atherosclerotic lesions of the vascular bed are featured with the increased content of CHS [10]. Early intimal thickening of the vascular wall in atherogenesis is also linked with accumulation of CHS [7].

Exposition of chondroitin sulphate proteoglycan (CSPG) in the artery sub-endothelium after intervention and stent placement [42] was noted in atherosclerotic New Zealand white rabbits. CSPG was the aim for binding the cationic liposomes (with prednisolone), contributing to the reliable depression of growth of intra-stent neointimae. These data approve the possibility and efficiency of use of the components of vascular cell glycocalyx for targeted delivery of medical substances [43]. Moreover, glycocalyx of erythrocytes may protect the tissue plasminogen activator (tPA) bounded with it against inhibition interaction with inhibitor of plasminogen activator of type 1 (PAI-1), destroying the local electrostatic interactions among them, not disturbing the binding of tPA with fibrin and plasminogen [44]. Such stabilization by glycocalyx makes it possible to offer biotinilated components (tPA and erythrocytes), bounded via streptavidin, for thrombosis prophylaxis in patients with high risk of cerebral or vascular lesion $[45,46]$. The noted effects approve the importance of network of distribution of coulomb charges during interaction with glycocalyx, and this may explain the high efficiency of antithrombotic action of bienzyme SOD-CHSCAT conjugate. This derivative does not cause disturbance effect on the hemodynamic system of the rats and rabbits; it has the acceptable parameters of acute toxicity and evident antithrombotic potential [10]. The accumulated data contribute to the promotion of the received derivative up to the status of drug candidate.

\section{SCHEDULED DEVELOPMENT OF SCIENTIFIC AND PRODUCTIVE BACKGROUND}

Scientific development of the new biopharmaceutical substances (biopharmaceuticals) implies the development of methods of medical biotechnology, slowly but inevitably becoming the element of pharmaceutical industry. Development of the later is based on progress in systems biology amending to our knowledge and understanding of 
health protection, contributing to switch to the targeted work-out of biopharmaceuticals. Development of bioeconomy as the new model of economic activity leads to establishment of the new types of the enterprise, and to the new life of the acting companies. Establishment of the plants and factories manufacturing certified bioreactives (recombinant proteins, RNA, DNA, their fragments, blood proteins, enzymes, peptides, vaccines, etc.), toxicology centers, the medical organizations for clinical trials of bioderivatives are evidently the limiting stage of practical use of biopharmaceuticals, and the enzyme antioxidants are the biopharmaceuticals of the special interest. Such approach requires important, regular and sufficient financial support. Harmonic combination of stage of scientific, preclinical, biotechnological, toxicological, clinical, technological developments is the pre-condition for effective output of the medical substances of the new generation.

\section{SUMMARY}

Oxidative stress is the peculiarity of all cardiovascular diseases. Reactive oxygen species may contribute to initiation and development of pathological process. Antioxidants which are capable to block it, were efficient in experimental trials, nevertheless, the data of the clinical trials appeared much more modest. This contributed to the sceptic evaluation of antioxidants by the clinicians. Analysis of limitations in the clinical trials performed with them leaves two ways for development of antioxidant therapy. The first way is the accurate, step-by-step research of antioxidants according to the strict, professionally designed protocol of the trials. Many publications still appear about such trials, nevertheless their number decreases with the time. The second direction is to find the break-through data on the new antioxidant substances, thus accelerating the development of antioxidant therapy. Burst of the recent publications about enzyme antioxidants enables to speak about the next stage of formation of antioxidant treatment. EC-SOD is of important interest for the researchers, as it appeared the efficient marker and corrector of condition in case of hypertension, heart failure, diabetes mellitus, atherosclerosis. The researches of antioxidant efficacy of the other enzymes having autonomic functions, such as are SOD-1, SOD-2, CAT, continue (co-factor, the reducted glutathione, is required for activity of glutathione peroxidase, and its quantity in case of oxidative stress is rather limited, that reduces the importance of this enzyme for the medical purposes). The methods of biological and chemical synthesis are used to obtain the enzymes with connected catalytic activity. Derivatives of this kind (like SOD-CHS-CAT conjugate) are very promising for the future biopharmaceutical research. Nevertheless, its success is subject of the efforts of specialists of various disciplines, the actual conditions of becoming and progress of medical biotechnology, pharmaceutical industry, bioeconomy. At the present time main focus in trials of enzyme antioxidants is made on scientific and preclinical stages of work.

\section{ACKNOWLEDGEMENTS}

The authors sincere recognize and highly appreciate the support of research and efficient discussions with professors E.I. Chazov, V.N. Smirnov, A.M. Egorov, E.V. Arzamastcev, V.I. Kapelko, V.Z. Lankin, E.K. Ruuge, A.K.
Tichase. This work was performed due to the support of the grants of RFBR 07-04-12057-ofi, 09-08-00023 and Rosmedtechnologies.

$\begin{array}{ll}\text { ABBREVIATIONS } \\ \text { AMI } & =\text { Acute Myocardial Infarction } \\ \text { CAT } & =\text { Catalase } \\ \text { CHS } & =\text { Chondroitin Sulphate } \\ \text { CSPG } & =\text { Chondroitin Sulphate Proteoglycan } \\ \text { EC-SOD } & =\text { Extracellular Superoxide Dismutase } \\ \text { NO } & =\text { Nitric Oxide } \\ \mathrm{O}_{\overline{2}} & \text { Superoxide Radical } \\ \text { oxLDL } & \text { Oxidized Forms of Low-Density Lipoproteins } \\ \text { PAI-1 } & \text { Plasminogen Activator Inhibitor of Type 1 } \\ \text { SOD } & =\text { Superoxide Dismutase } \\ \text { SOD-1 } & \text { Cytosolic Dimeric Cu,Zn-SOD } \\ \text { SOD-3 } & =\text { Tetramer of Cu,Zn-SOD, Extracellular } \\ \text { tPA } & =\text { Superoxide Dismutase }\end{array}$

\section{REFERENCES}

[1] Miura, T.; Miki, T. Limitation of myocardial infarct size in the clinical setting: current status and challenges in translating animal experiments into clinical therapy. Basic Res. Cardiol., 2008, 103, 501-513.

[2] Maksimenko, A.V. Thrombolysis research - new objectives after a shift of accent. Med. Sci. Monit, 2002, 8, RA13-RA21.

[3] Dubinina, E.E. Oxygen metabolism products in the functional activity of cells; Medicinal Press: Sankt-Petersburgh, 2006. (in Russian)

[4] Mentschikova, E.B.; Zenkov, N.K.; Lankin, V.Z.; Bondar, I.A.; Trufakin, V.A. Oxidative stress. Pathological states and diseases; ARTA: Novosibirsk, 2008. (in Russian)

[5] Dirksen, M.T.; Laarman, G.T.; Simoons, M.L.; Duncker. D.J.G.M. Reperfusion injury in humans: a review of clinical trials on reperfusion injury inhibitory strategies. Cardiovasc. Res., 2007, 74, 343-355.

[6] Kloner, R.A. Does reperfusion injury exist in humans? J. Am. Coll. Cardiol., 1993, 21, 537-545.

[7] Maksimenko, A.V. Effects of glycosaminoglycans in vascular events. Pharm. Chem. J., 2008, 42, 3-13. (in Russian)

[8] Wight, T.N.; Merrilees, M.J. Proteoglycans in atherosclerosis and restenosis: key role for versican. Circ. Res., 2004, 94, 1158-1167.

[9] Mentschikova, E.B.; Lankin, V.Z.; Zenkov, N.K.; Bondar, I.A.; Krugovykh, N.F.; Trufakin, V.A. Oxidative stress. Prooxidants and antioxidants; Slovo: Moscow, 2006. (in Russian)

[10] Maksimenko, A.V. Experimental antioxidant biotherapy for protection of the vascular wall by modified forms of superoxide dismutase and catalase. Curr. Pharm. Des., 2005, 11, 2007-2016.

[11] Bhatt, D.L.; Pashkow, F.Y. Oxidative stress and heart disease. Am. J. Cardiol., 2008, 101, 1D-86D.

[12] Tsujita, K.; Shimomura, H.; Kaikita, K.; Kawano, H.; Hokamaki, J.; Nagayoshi, Y.; Sakamoto, T.; Yoshimura, M.; Arai, H.; Ogawa, H. Effect of edaravone on reperfusion injury in patients with acute myocardial infarction. Am. J. Cardiol., 2004, 94, 481-484.

[13] Jitsuiki, D.; Higashi, Y.; Goto, C.; Kimura, M.; Noma, K.; Hara, K.; Nakagawa, K.; Oshima, T.; Chayama, K.; Yoshizumi, M. Effect of edaravone, a novel free radical scavenger, on endothelium-dependent vasodilation in smokers. Am. J. Cardiol., 2004, 94, 1070-1073.

[14] Tiano, L.; Belardinelli, R.; Carnevali, P.; Principi, F.; Seddaiu, G.; Littarru, G.P. Effect of coenzyme Q10 administration on endothelial function and extracellular superoxide dismutase in patients with ischaemic heart disease: a double-blind, randomized controlled study. Eur. Heart. J., 2007, 28, 2249-2255. 
[15] Kaliora, A.C.; Dedoussis, G.V.Z.; Schmidt, H. Dietary antioxidant in preventing atherogenesis. Atherosclerosis, 2006, 187, 1-17.

[16] Chu, Y.; Iida, S.; Lund, D.D.; Weiss, R.M.; DiBona, G.F.; Watanabe, Y.; Faraci, F.M.; Heistad, D.D. Gene transfer of extracellular superoxide dismutase reduces arterial pressure in spontaneously hypertensive rats: role of heparin binding domain. Circ. Res., 2003, 92, 461-468.

[17] Heistad, D.D. Oxidative stress and vascular disease. 2005. Duff lecture. Arterioscler. Thromb. Vasc. Biol., 2006, 26, 689-695.

[18] Petersen, S.V.; Oury, T.D.; Ostergaard, L.; Valnickova, Z.; Wegrzyn, J.; Thøgersen, I.B.; Jacobsen, C.; Bowler, R.P.; Fattman, C.L.; GrapoJ.D.; Enghild, J.J. Extracellular superoxide dismutase (EC-SOD) binds to type 1 collagen and protects against oxidative fragmentation. J. Biol. Chem., 2004, 279, 13705-13710.

[19] Nguyen, A.D.; Itoh, S.; Jeney, V.; Yanagisawa, H.; Fujimoto, M.; Ushio-Fukai, M.; Fukai, T. Fibulin-5 is a novel binding protein for extracellular superoxide dismutase. Circ. Res., 2004, 95, 10671074.

[20] Onry, T.D.; Day, B.J.; Crapo, J.D. Extracellular superoxide dismutase: a regulator of nitric oxide bioavailability. Lab. Invest., 1996, 75, 617-636.

[21] Fukai, T.; Folz, R.Z.; Landmesser, U.; Harrison, D.G. Extracellular superoxide dismutase and cardiovascular disease. Cardiovasc. Res., 2002, 55, 239-249.

[22] Landmesser, U.; Merten, R.; Spiekermann, S.; Büttner, K.; Drexler, H.; Hornig, B. Vascular extracellular superoxide dismutase activity in patients with coronary artery disease, relation to endotheliumdependent vasodilation. Circulation, 2000, 101, 2264-2270.

[23] Tasaki, H.; Yamashita, K.; Tsutsui, M.; Kamezaki, F.; Kubara, T.; Tanaka, S.; Sasaguri, Y.; Adachi, T.; Nakashima, Y. Heparinreleased extracellular superoxide is reduced in patients with coronary artery atherosclerosis. Atherosclerosis, 2006, 187, 131138.

[24] Wolin, M.S. Interactions of oxidants with vascular signaling systems. Arterioscler. Thromb. Vasc. Biol., 2000, 20, 1430-1442.

[25] Jung, O.; Marklund, S.L.; Xia, N.; Busse, R.; Brandes, R.P. Inactivation of extracellular superoxide dismutase contributes to the development of high-volume hypertension. Arterioscler. Thromb. Vasc. Biol., 2007, 27, 470-477.

[26] Gongora, M.C.; Qin, Z.; Laude, K.; Kim, H.W.; McCann, L.; Folz, J.R.; Dikalov, S.; Fukai, T.; Harrison, D.G. Role of extracellular superoxide dismutase in hypertension. Hypertension, 2006, 48, 473-481.

[27] Jung, O.; Marklund, S.L.; Geiger, H.; Pedrazzini, T.; Busse, R.; Brandes, R.P. Extracellular superoxide dismutase is a major determinant of nitric oxide bioavailability: in vivo and ex vivo evidence from EC-SOD deficient mice. Circ. Res., 2003, 93, 622629.

[28] Welch, W.J.; Chabrashvili, T.; Solis, G.; Chen, Y.; Gill, P.S.; Aslam, S.; Wang,X.; Ji, H.; Sandberg, K.; Jose, P.; Wilcox, C.S. Role of extracellular superoxide dismutase in the mouse angiotensin slow press or response. Hypertension, 2006, 48, 934941.

[29] Carlsson, L.M.; Marklund, S.L.; Edlund, T. The rat extracellular superoxide dismutase dimer is converted to a tetramer by the exchange of a single amino acid. Proc. Natl. Acad. Sci. USA, 1996, 93, 5219-5222.

[30] Marklund, S.L. Extracellular superoxide dismutase in human tissues and human cell lines. J. Clin. Invest., 1984, 74, 1398-1403.

[31] Stralin, P.; Karlsson, K.; Johansson, B.O.; Marklund, S.L. The interstitium of the human arterial wall contains very large amounts of extracellular superoxide dismutase. Arterioscler. Thromb. Vasc. Biol., 1995, 15, 2032-2036.

[32] Levonen, A.L.; Vahakangas, E.; Koponen, J.K.; Yla-Herttuala, S. Antioxidant gene therapy for cardiovascular disease. Current status and future perspectives. Circulation, 2008, 117, 2142-2150.
[33] Stocker, R.; Pererella, M.A. Hem oxigenase-1: a novel drug target for atherosclerotic diseases? Circulation, 2006, 114, 2178-2189.

[34] Bräsen, J.H.; Leppänen, O.; Inkala, M.; Heikura, T.; Levin, M.; Ahrens, F.; Rutanen, J.; Pietsch, H.; Bergqvist, D.; Levonen, A.-L.; Basu, S.; Zeller, T.; Klöppfel, G.; Laukkanen, M.O.; Ylä-Herttuala, S. Extracellular superoxide dismutase accelerates endothelial recovery and inhibits in-stent restenosis in stented atherosclerotic Watanabe heritable hyperlipidemic rabbit aorta. J. Am. Coll. Cardiol., 2007, 50, 2249-2253.

[35] Zhou, L.; Xiang, W.; Potts, J.; Floyd, M.; Sharan, C.; Yang, H.; Ross, J.; Nyanda, A.M.; Guo, Z. Reduction in extracellular superoxide dismutase activity in African-American patients with hypertension. Free Radic. Biol. Med., 2006, 41, 1384-1391.

[36] Fukai, T. Extracellular SOD inactivation in high-volume hypertension: Role of hydrogen peroxide. Arterioscler. Thromb. Vasc. Biol., 2007, 27, 442-444.

[37] Lin, S.J.; Shyue, S.K.; Liu, P.L.; Chen, Y.H.; Ku, H.H.; Chen, J.W.; Tam, K.B.; Chen, Y.L. Adenovirus-mediated overexpression of catalase attenuates oxLDL-induced apoptosis in human aortic endothelial cells via AP-1 and C-Jun N-terminal kinase pathways. J. Mol. Cell. Cardiol., 2004, 36, 129-139.

[38] Lin, S.J.; Shyue, S.K.; Shih, M.C.; Chu, T.H.; Chen, Y.H.; Ku, H.H.; Chen, J.W.; Tam, K.B.; Chen, Y.L. Superoxide dismutase and catalase inhibit oxidized low-density lipoprotein-induced human aortic smooth muscle cell proliferation: role of cell-cycle regulation, mitogen-activated protein kinases, and transcription factors. Atherosclerosis, 2007, 190, 124-134.

[39] Yang, H.; Roberts, L.J.; Shi, M.J.; Zhou, L.C.; Ballard, B.R.; Richardson, A.; Guo, Z.M. Retardation of atherosclerosis by overexpression of catalase or both $\mathrm{Cu}, \mathrm{Zn}-\mathrm{SOD}$ dismutase and catalase in mice lacking apolipoprotein E. Circ. Res., 2004, 95, 1075-1081.

[40] Van Empel, V.P.; Bertrand, A.T.; van Oort, R.J.; van der Nagel, R.; Engelen, M.; van Rijen, H.V.; Doevendans, P.A.; Crijns, H.J.; Ackerman, S.L.; Sluiter, W.; De Windt, L.J. EUK-8, a superoxide dismutase and catalase mimetic, reduces cardiac oxidative stress and ameliorates pressure overload-induced heart failure in the Harlequin mouse mutant. J. Am. Coll. Cardiol., 2006, 48, 824-832.

[41] Maksimenko, A.V.; Golubykh, V.L.; Tischenko, E.G. The combination of modified antioxidant enzymes for anti-thrombotic protection of the vascular wall: the significance of covalent connection of superoxide dismutase and catalase activities. $J$. Pharm. Pharmacol., 2004, 56, 1463-1468.

[42] Joner, M.; Morimoto, K.; Kasukawa, H.; Steigerwald, K.; Merl, S.; Nakazawa, G.; John, M.C.; Finn, A.V.; Acampado, E.; Kolodgie, F.D.; Gold, H.K.; Virmani, R. Site-specific targeting of nanoparticles prednisolone reduces in-stent restenosis in a rabbit model of established atheroma. Arterioscler. Thromb. Vasc. Biol., 2008, 28, 1960-1966.

[43] Sarembock, I.J. From systemic shotgun to site-specific nanoparticle-targeted delivery: A new paradigm for drug delivery. Arterioscler. Thromb. Vasc. Biol., 2008, 28, 1879-1881.

[44] Ganguly, K.; Murciano, J.C.; Westrick, R.; Leferovich, J.; Cines, D.B.; Muzykantov, V.R. The glycocalyx protects erythrocytebound tissue-type plasminogen activator from enzymatic inhibition. J. Pharmacol. Exp. Ther., 2007, 321, 158-164.

[45] Danielyan, K.; Ganguly, K.; Ding, B.S.; Atochin, D.; Zaitsev, S.; Murciano, J.C.; Huang, P.L.; Kasner, S.E.; Cines, D.V.; Muzykantov, V.R. Cerebrovascular thromboprophylaxis in mice by erythrocyte-coupled tissue-type plasminogen activator. Circulation, 2008, 118, 1442-1449.

[46] Schneider, D.J.; Sobel, B.E. A novel role for tissue-type plasminogen activator: Prevention of thromboembolic occlusion. Circulation, 2008, 118, 1408-1409. 